\title{
Association between mutations in the gap junction $\beta 4$ gene and nonsyndromic hearing loss: Genotype-phenotype correlation patterns
}

\author{
TUNG-CHENG LI ${ }^{1}$, WEN-HUNG WANG ${ }^{2,3}$, CHUAN LI ${ }^{4,5}$ and JIANN-JOU YANG ${ }^{4,5}$ \\ ${ }^{1}$ Institute of Medicine, Chung Shan Medical University, Taichung 402; ${ }^{2}$ Department of Otolaryngology, \\ Chang Gung Memorial Hospital, Chiayi $613 ;{ }^{3}$ Department of Otolaryngology, Cathay General Hospital, \\ Taipei 106; Departments of ${ }^{4}$ Biomedical Sciences and ${ }^{5}$ Medical Research, \\ Chung Shan Medical University Hospital, Taichung 402, Taiwan, R.O.C.
}

Received December 10, 2013; Accepted September 12, 2014

DOI: $10.3892 / \mathrm{mmr} .2014 .2725$

\begin{abstract}
Numerous studies have confirmed that gap junctions, composed of connexin $(\mathrm{Cx})$ protein, are essential for auditory function. However, few studies have investigated the correlation between variants in the gap junction $\beta 4$ (GJB4) gene and phenotype in patients with nonsyndromic hearing loss. Our previous study identified 11 patients with GJB4 gene variants in 253 unrelated patients with nonsyndromic hearing loss. In the present study, the phenotype-genotype correlation was examined in the 11 deaf patients with the different variants of GJB4. Analytical results revealed that the majority of probands had congenital hearing loss, which was bilateral, stable and without associated dermatological manifestations or morphological changes of the inner ear. An audiometric profile, including the observed consistency with severe-profound and flat shape dominance, may enable screening for variants of GJB4. On the basis of the above results, it was hypothesized that $G J B 4$ may be a genetic risk factor for the development of nonsyndromic hearing loss and the data from the present study can be used to direct the clinical evaluation and effectively manage the care of families of children with GJB4.
\end{abstract}

\section{Introduction}

Hearing impairment is the most common sensory disorder worldwide (1) and genetic inheritance presents a major source of the auditory system dysfunction resulting in hearing loss (2). Presently, 54 gene loci associated with an autosomal dominant mode of inheritance and 67 gene loci associated with an autosomal recessive mode of inheritance have been identified,

Correspondence to: Dr Jiann-Jou Yang, Department of Biomedical Sciences, Chung Shan Medical University, 110 Chien-Kun North Road, Taichung 402, Taiwan, R.O.C.

E-mail: jiannjou@csmu.edu.tw

Key words: connexin 30.3, hearing loss, phenotype, genotype, gap junction $\beta 4$, gap junction of which seven are $\mathrm{X}$ chromosome-linked and four are mitochondrial (3). The cochlea is a complex organ in the ear, which is composed of several cell types and specialized regions that are involved in the normal process of hearing. A number of genes have been associated with hearing loss and several corresponding proteins have been identified as being expressed in the cochlea. Ionic homeostasis in the cochlear duct is associated with a several genes associated with deafness (4). In mice, endolymph (the fluid surrounding the upper surface of the hair cell) has a high concentration of potassium and a low concentration of sodium, and is maintained at a high positive resting potential of approximately $+100 \mathrm{mV}$. This high resting potential is considered to be essential for the normal functioning of hair cells as, when its value is reduced to zero, deafness occurs (5).

Communication between the majority of cells in animal tissues is mediated by unique intercellular cytoplasmic channels, gap junctions, spanning across two cell membranes. These cell-to-cell channels consist of assemblies of proteins termed connexins (Cxs) or pannexins in vertebrates and innexins in invertebrates (6). Cxs belong to a protein family of $>20$ members, each of which is encoded by a different gene and they are assigned a number which is associated with their approximate molecular weights. Cxs share a common structure of four transmembrane segments, which extend into two extracellular and three cytoplasmic domains (7). Gap junction intercellular communication has a range of functions in order to meet the requirements of the organs, tissues and cell groups in which the Cx genes are expressed (8), and the importance of these gap junctions in auditory functions has been confirmed by numerous studies (9-13). In the sensory epithelia of the inner ear, gap junction channels are important in the recycling of potassium ions that enter the hair cells and are also involved in auditory signal transduction (14).

Immunolabeling analysis has identified several types of $\mathrm{Cx}$ product, including Cx26, Cx29, Cx30, Cx31 and Cx43, in the mature cochlea (10-12,15-17). Through immunohistochemiical and reverse transcription-quantitative polymerase chain reaction analyses, our previous study indicated that $\mathrm{Cx} 30.3$ is present and localized in the rat cochlea (18). In addition, a study of 555 deaf patients revealed a common $(4.1 \%$; 23/555) 
frameshift mutation (c.154del4) in gap junction $\beta 4$ (GJB4, also termed $\mathrm{Cx} 30.3$ ) in deaf individuals (18). In the study, five amino acid variants (c.307 C>T, c.371 G>A, c.478 C>T, c.507 $\mathrm{C}>\mathrm{G}$ and c.611 $\mathrm{A}>\mathrm{C}$ ) were detected in deaf individuals without skin disorders (19). In our previous genetic survey of 373 individuals, including 253 with nonsyndromic deafness and 120 with normal hearing, 11 mutations were detected in the patients with hearing loss (20). However, the correlation between the GJB4 gene mutations and the audiology phenotype in deaf patients was not examined. Therefore, the present study investigated the phenotype-genotype correlation in deaf patients with mutations in GJB4, the results of which may provide assistance in the clinical evaluation and effective management of care for families of children with GJB4.

\section{Materials and methods}

Patient selection. A total of 253 individuals with hearing loss were screened for GJB4 variants in the present study. For the patients with hearing loss, a total of 173 school children were selected from the National Tainan School for the Deaf (Tainan, China) and 80 individuals with hearing loss, who were managed at the Chang Gung Memorial Hospital (Chiayi, China), were selected. The frequency range of hearing loss was between 250 and $8,000 \mathrm{~Hz}$, with a mean threshold (500, $1,000,2,000$ and $4,000 \mathrm{~Hz}$ ) of $>40 \mathrm{~dB}$ in the right and left ears. All probands were 17 years old or younger at the time of molecular diagnosis. In the present study, the 11 patients with GJB4 missense and nonsense mutations had complete audiograms and were used for analysis.

Patients with syndromic hearing loss or environment-associated hearing loss were excluded from the present study, as determined by an otorhinolaryngologist. The complete medical history of each child was obtained to determine the age of onset of deafness and to exclude the possibility of environmental causes, including maternofetal infection, perinatal complications, meningitis, mumps, prenatal or postnatal drug ototoxicity and acoustic trauma. All procedures were approved by the Institutional Review Board of Chung Gung Memorial Hospital (96-1294B). Written informed consent was obtained from all patients.

Clinical evaluation. The genetic and audiological data were categorized according to recommendations on geneotype-phenotype correlations by the Genetic Deafness Study Group (21). According to these guidelines, the groups were recognized as follows: Mild hearing loss (20-40 dB), moderate hearing loss (41-70 dB), severe hearing loss (71-95 dB) and profound hearing loss ( $>95 \mathrm{~dB})$. The audiometric configurations were determined for each ear by differences in hearing level (HL) as follows: Ascending low frequency, $>15 \mathrm{~dB}$ difference in HL between the poorer low frequency thresholds and the higher frequencies; U-shaped mid frequency, $>15 \mathrm{~dB}$ difference in $\mathrm{HL}$ between thresholds at the poorest mid-frequencies and those at higher and lower frequencies; gently sloping high frequency, 5-29 dB difference in HL between the mean thresholds at 0.5 and $1 \mathrm{kHz}$ and at 4 and $8 \mathrm{kHz}$; steeply sloping high frequency, $>30 \mathrm{~dB}$ difference in HL between the above-mentioned frequencies; and flat, $<15 \mathrm{~dB}$ difference in HL between the mean thresholds at 0.25 and $0.5 \mathrm{kHz}, 1$ and $2 \mathrm{kHz}$ and 4 and $8 \mathrm{kHz}$.
Asymmetric HL was defined as an interaural pure tone average (PTA) difference of $>10 \mathrm{~dB}$ in at least two frequencies.

Computed tomography (CT) of the inner ear. CT images of the inner ears were examined in 11 probands in the cohort of the present study. All the images examined were high resolution 1-mm contiguous, axial and coronal images of the temporal bones. Digital or printed images were evaluated for abnormalities of the cochlea, vestibule, semicircular canals and endolymphatic aqueduct.

\section{Results}

Severity and configuration of hearing impairment and genotype. In our previous study, a total of nine different GJB4 mutations were identified in 11 of the 253 probands (19). Of these mutations, eight were missense variants that led to amino acid substitution in the encoded proteins and one was a nonsense mutation. No vestibular symptoms or skin disorders were observed in any individual. Genetic assessment facilitates the determination of the cause of deafness and the prediction of the degree of hearing impairment and language development (22). Therefore, the present study investigated the phenotype-genotype correlation in the 11 deaf patients with mutations of GJB4. The severity of hearing impairment was assessed in the 11 patients with the GJB4 mutations (Table I; Fig. 1), and the four-frequency PTA was calculated as the average of air-conduction thresholds at $500,1,000,2,000$ and $4,000 \mathrm{~Hz}$. The mean ( \pm standard deviation) threshold of hearing for all GJB4 mutations was $97.16 \mathrm{~dB}( \pm 13.52 \mathrm{~dB})$. In the present study, 10 probands with the GJB4 mutation were observed to have symmetrical HL. Asymmetric HL was observed in only one proband (TDF547), with an interaural PTA difference of $20 \mathrm{~dB}$. This proband had a c.109G>A/WT heterozygous genotype. In addition, one proband (TDF521) was identified with a compound missense heterzogous mutation (c.376G $>\mathrm{A} / \mathrm{c} .507 \mathrm{C}>\mathrm{G}$ ) of $\mathrm{GJB} 4$ and had more severe hearing loss, compared with the proband exhibiting a heterozygous missense mutation (c.376G $>\mathrm{A} / \mathrm{wt}$ ), in the right and left ears (Fig. 2).

Cx30.3 protein structure and hearing loss. Similar to other Cx proteins, Cx30.3 consists of four transmembrane (TM) domains, TM1 (amino acid 21-40), TM2 (amino acid 76-98), TM3 (amino acid 127-149) and TM4 (amino acid 188-210). These are linked by one cytoplasmic and two extracellular loops with cytoplasmic C- and N-terminal ends. The p.R22C and p.V37M substitutions detected in the present study occurred in TM1 of Cx30.3, and the p.E67L and p.C169X substitutions occurred in the first extracellular loop (E1) and the second extracellular loop (E2) of Cx30.3, respectively. In addition, three variants, p.R98C, p.R124W and p.G126T, were located at the cytoplasmic domain and two variants, $\mathrm{p} . \mathrm{H} 221 \mathrm{Y}$ and p.T233L, were located at the C-terminal domain. The relative predictive values of PTA were then examined in the right and left ears of the patients with the GJB4 mutations (Table I). The hearing threshold results revealed that cytoplasmic linking (CL) domain mutations of the Cx30.3 protein had a PTA of 68-72 dB, with the exception of the p.R124W missense mutation. However, the mean PTA was $>96 \mathrm{~dB}$ in the other domains of the $\mathrm{Cx} 30.3$ protein (Table I), suggesting that the 
Table I. Audibility thresholds for air conduction in pure tone audiometry of the 11 patients with gap junction $\beta 4$ missense and nonsense variants at frequencies between 250 and $8,000 \mathrm{~Hz}$.

\begin{tabular}{|c|c|c|c|c|c|c|c|c|c|c|}
\hline \multirow[b]{2}{*}{ Patient } & \multirow{2}{*}{$\begin{array}{l}\text { Genotype variant } \\
\text { (amino acid change) }\end{array}$} & \multirow{2}{*}{$\begin{array}{l}\text { Protein } \\
\text { domain }\end{array}$} & \multicolumn{7}{|c|}{ Frequency (Hz) } & \multirow{2}{*}{$\begin{array}{l}\text { Mean } \\
\text { threshold }^{\mathrm{a}}\end{array}$} \\
\hline & & & Ear & 250 & 500 & 1,000 & 2,000 & 4,000 & 8,000 & \\
\hline \multirow[t]{2}{*}{ KDF026 } & c. $64 \mathrm{C}>\mathrm{T} / \mathrm{WT}$ & M1 & $\mathrm{R}$ & AR & 95 & 100 & 100 & 90 & AR & $96.3 \pm 4.8$ \\
\hline & $(\mathrm{pR} 22 \mathrm{C})$ & & $\mathrm{L}$ & AR & 105 & 95 & 110 & 105 & $\mathrm{AR}$ & $103.8 \pm 6.3$ \\
\hline \multirow[t]{2}{*}{ TDF547 } & c. $109 \mathrm{G}>\mathrm{A} / \mathrm{WT}$ & M1 & $\mathrm{R}$ & 70 & 90 & 100 & 100 & 110 & 100 & $100.0 \pm 8.2$ \\
\hline & (p.V37M) & & $\mathrm{L}$ & 90 & 100 & 100 & 100 & 110 & 100 & $102.5 \pm 5.0$ \\
\hline \multirow[t]{2}{*}{ TDF553 } & c. $109 \mathrm{G}>\mathrm{A} / \mathrm{WT}$ & M1 & $\mathrm{R}$ & 95 & 100 & 100 & 105 & 115 & 100 & $105.0 \pm 7.1$ \\
\hline & (p.V37M) & & $\mathrm{L}$ & 105 & 115 & 120 & 120 & 115 & 100 & $117.5 \pm 2.9$ \\
\hline \multirow[t]{2}{*}{ TDF067 } & c $.199 \mathrm{G}>\mathrm{A} / \mathrm{WT}$ & $\mathrm{El}$ & $\mathrm{R}$ & 110 & 110 & 110 & 110 & 110 & 110 & $110.0 \pm 0.0$ \\
\hline & (p.E 67L) & & $\mathrm{L}$ & 110 & 110 & 110 & 110 & 110 & 110 & $110.0 \pm 0.0$ \\
\hline \multirow[t]{2}{*}{ CDF006 } & c. 292 C>T/WT & CL & $\mathrm{R}$ & 70 & 70 & 75 & 70 & 75 & 75 & $72.5 \pm 2.9$ \\
\hline & $(\mathrm{pR} .98 \mathrm{C})$ & & $\mathrm{L}$ & 60 & 65 & 75 & 70 & 70 & 70 & $70.0 \pm 4.1$ \\
\hline \multirow[t]{2}{*}{ LDF011 } & c. $370 \mathrm{C}>\mathrm{T} / \mathrm{WT}$ & CL & $\mathrm{R}$ & AR & 95 & 105 & 105 & 100 & AR & $101.3 \pm 4.8$ \\
\hline & (p.R124W) & & $\mathrm{L}$ & AR & 90 & 100 & 95 & 100 & AR & $96.3 \pm 4.8$ \\
\hline \multirow[t]{2}{*}{ TDF512 } & c376G >A/WT & CL & $\mathrm{R}$ & 60 & 65 & 65 & 65 & 80 & AR & $68.8 \pm 7.5$ \\
\hline & (p.G126T) & & $\mathrm{L}$ & 55 & 60 & 75 & 80 & 80 & AR & $73.8 \pm 9.5$ \\
\hline \multirow[t]{2}{*}{ LDF014 } & c. $.507 \mathrm{C}>\mathrm{A} / \mathrm{WT}$ & E2 & $\mathrm{R}$ & 55 & 85 & 95 & 100 & 110 & 100 & $97.5 \pm 10.4$ \\
\hline & (p.0 169X) & & $\mathrm{L}$ & 55 & 85 & 95 & 100 & 110 & 100 & $97.5 \pm 10.4$ \\
\hline \multirow[t]{2}{*}{ KDF012 } & c. $661 \mathrm{C}>\mathrm{T} / \mathrm{WT}$ & $\mathrm{C}$ & $\mathrm{R}$ & $\mathrm{AR}$ & 100 & 100 & 100 & 110 & AR & $102.5 \pm 5.0$ \\
\hline & (p.H221Y) & & $\mathrm{L}$ & AR & 90 & 100 & 110 & 110 & AR & $102.5 \pm 9.6$ \\
\hline \multirow[t]{2}{*}{ TD F035 } & c. $698 \mathrm{C}>\mathrm{A} / \mathrm{WT}$ & $\mathrm{C}$ & $\mathrm{R}$ & 90 & 100 & 100 & 110 & 110 & 100 & $105.0 \pm 5.8$ \\
\hline & (p.T233L) & & $\mathrm{L}$ & 90 & 110 & 100 & 110 & 110 & 100 & $107.5 \pm 5.0$ \\
\hline \multirow[t]{2}{*}{ TDF521 } & c. $376 \mathrm{G}>\mathrm{A} / \mathrm{c} .507 \mathrm{C}>\mathrm{G}$ & CL/E2 & $\mathrm{R}$ & 80 & 85 & 90 & 105 & 110 & 100 & $97.5 \pm 11.9$ \\
\hline & (p.G126T)/(p.C169W) & & $\mathrm{L}$ & 80 & 95 & 100 & 105 & 100 & 95 & $100.0 \pm 4.1$ \\
\hline
\end{tabular}

${ }^{\mathrm{a}}$ Mean, calculated from the frequencies of 500, 1,000, 2,000 and $4000 \mathrm{~Hz}$. AR, absent response in the maximum intensity of the device; R, right ear; L, left ear; E1, first extracellular loop; E2, second extracellular loop; M1, transmembrane domain 1; CL, cytoplasmic linking domain.

Table II. Comparison of GJB4 and GJB2 on the basis of audiogram shapes.

\begin{tabular}{|c|c|c|c|c|c|c|c|c|}
\hline \multirow[b]{2}{*}{$\begin{array}{l}\text { Audiogram } \\
\text { shape }\end{array}$} & \multicolumn{2}{|c|}{$\begin{array}{l}\text { Present study } \\
\text { GJB4 }\end{array}$} & \multicolumn{2}{|c|}{$\begin{array}{l}\text { Present study } \\
\text { GJB2 }\end{array}$} & \multicolumn{2}{|c|}{$\begin{array}{c}\text { Hişmi et al (21) } \\
\text { GJB2 }\end{array}$} & \multicolumn{2}{|c|}{$\begin{array}{l}\text { Liu et al (22) } \\
\text { GJB2 }\end{array}$} \\
\hline & $\begin{array}{l}\text { Ears } \\
\text { (n) }\end{array}$ & $\%$ & $\begin{array}{c}\text { Ears } \\
\text { (n) }\end{array}$ & $\%$ & $\begin{array}{l}\text { Ears } \\
(\mathrm{n})\end{array}$ & $\%$ & $\begin{array}{l}\text { Probands } \\
\text { (n) }\end{array}$ & $\%$ \\
\hline Flat & 16 & 72.7 & 12 & 30 & 75 & 59.5 & 48 & 24.7 \\
\hline Sloping & 5 & 22.7 & 20 & 50 & 50 & 39.6 & 136 & 70.1 \\
\hline U-shaped & - & 0.0 & 4 & 10 & 1 & 0.8 & 10 & 5.1 \\
\hline Ascending & 1 & 4.6 & 4 & 10 & - & 0.0 & - & 0.0 \\
\hline Total & 22 & 100.0 & 40 & 100 & 126 & 100.0 & 194 & 100.0 \\
\hline
\end{tabular}

GJB4/2, gap junction $\beta 4 / 2$.

degree of PTA was lower in CL domain mutations compared with mutations in others domains of the Cx30.3 protein. In addition, in the proband with the c.507C $>$ A (p.C169X) mutation, the degree of hearing loss was more marked at high frequencies compared with low frequencies (Table I; Fig. 1).
Configuration of hearing loss. Furthermore, the relative frequencies of the configuration of hearing impairment in patients with GJB4 and GJB2 genotype variants in the present study were compared with those in previous studies by Hişmi et al (23) and Liu et al (24) (Table II; Fig. 3). The results indicated that the 

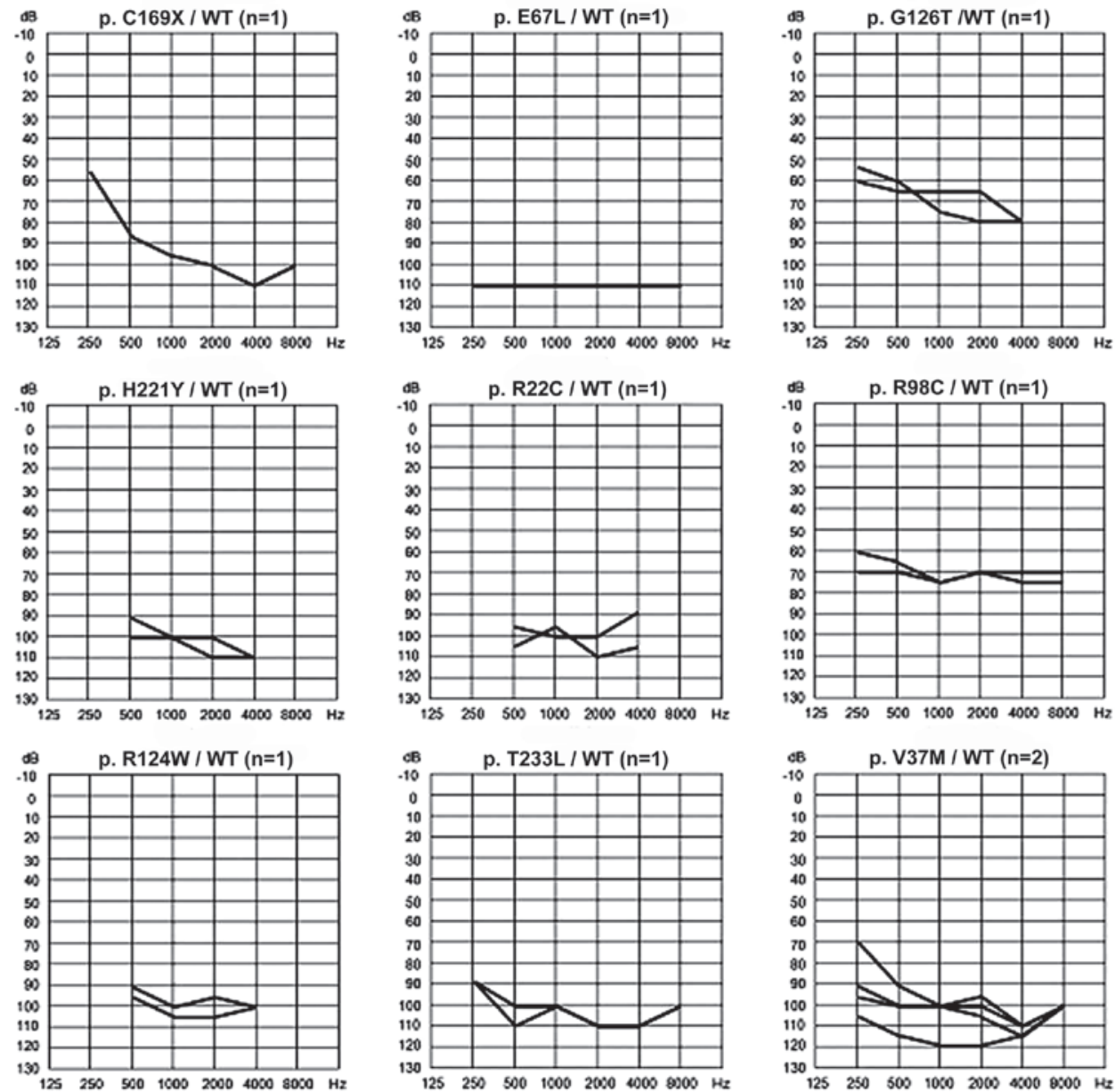

Figure 1. Audiogram of patients with heterozygous missense and nonsense variants of gap junction $\beta 4$.

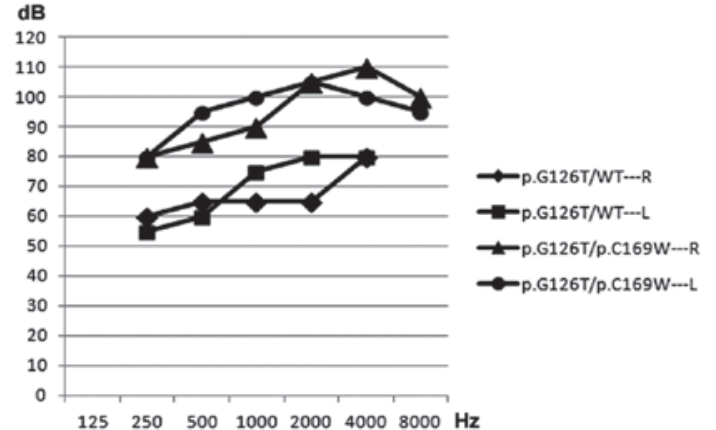

Figure 2. Audiogram of patients with a heterozygous gap junction $\beta 4$ mutation (p.G126T) and a compound heterozygous mutation (p.G126T/p.C169W). $\mathrm{R}$, right ear; L, left ear.

frequency of a flat audiometric configuration in patients with $G J B 4$ variants was significantly higher compared with that in patients with $G J B 2$ variants $(\mathrm{P}=0.016)$. Similarly, a significant difference was observed between the patients with GJB4 variants in the present study and the patients with GJB2 variants in the study by Liu et al $(\mathrm{P}<0.001)$. However, the difference in the frequency of this configuration between patients with $G J B 4$ in the present study and with GJB2 in the study by Hişmi et al was small $(\mathrm{P}=0.403)$. This may be due to the difference in the point mutation site in the GJB2 genotype, which was

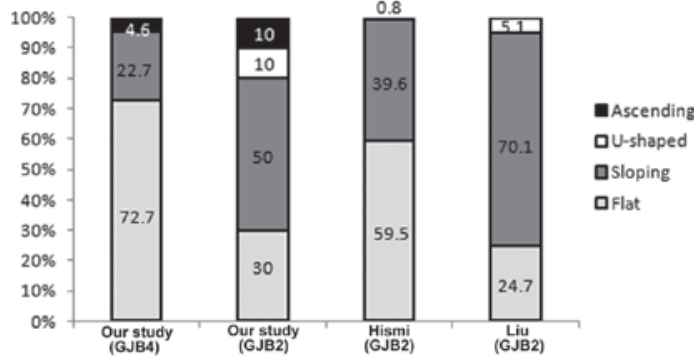

Figure 3. Relative frequencies of the configuration of hearing impairment in these genotypes. The actual number of patients is presented in Table II. The number of patients is detailed in each subgroup. $\mathrm{P}=0.016^{*}$ between $G J B 4$ and $G J B 2$ in the present study. $\mathrm{P}=0.403$ between $G J B 4$ in the present study and GJB2 in the study by Hişmi et al $(21) . \mathrm{P}<0.001^{*}$ between $G J B 4$ in the present study and GJB2 in the study by Liu et al $(22) .{ }^{*} \mathrm{P}<0.05$ indicates a statistically significant difference.

c. $35 \mathrm{delG}$ in the Hişmi et al study and c. $235 \mathrm{delC}$ in the present study, or due to different ethnicities resulting in different phenotypes. Therefore, in the present study, the flat shape was more predominant in patients with $G J B 4$ variants compared with $G J B 2$ variants, and this data may be applied to direct the clinical evaluation of children with GJB2 or GJB4.

CT images of the 11 patients were also analyzed. A total of 10 probands (20 ears) exhibited normal CT images of the 

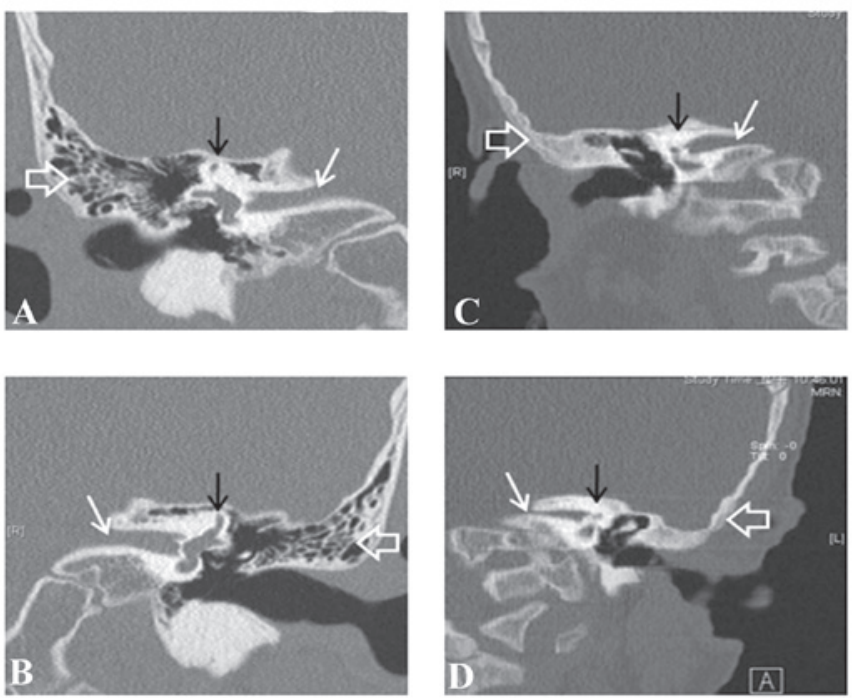

Figure 4. Computer tomograms of temporal bone in a normal subject and in a patient with inner ear and middle ear deformities. Normal IAC (white arrow), semicircular canals (black arrow) and mastoid air cells (open arrow) on the (A) right side and (B) left side in the normal subject. Bilateral IAC stenosis (white arrow), shortening of the superior and lateral semicircular canals (black arrow) and nonpneumatization of mastoid air cells (open arrow) on the (C) right side and (D) left side in a patient with the c.370 $\mathrm{C}>\mathrm{T}$ heterozygous genotype. IAC, internal auditory canal.

temporal bones. In one patient (LDF011) with a c.370 C>T heterozygous genotype, inner ear and middle ear deformities were observed (Fig. 4). The CT findings included bilateral stenosis of the inner auditory canal, which was greater on the left side, bilateral shortening of the superior and lateral semicircular canals and bilateral non-pneumatization of the mastoid air cells. In conclusion, only one of the 11 patients (9\%) with the GJB4 variant in the present study had a morphological abnormality of the inner ear, as indicated on the CT images. Therefore, the number of patients with morphological abnormalities of the inner ear in the cohort was low.

\section{Discussion}

Several genetic studies have revealed the importance of Cxs in normal cochlear function (Hereditary Hearing loss Homepage; http://hereditaryhearingloss.org/). Few studies have been conducted on the correlation of variants in the GJB4 gene and its phenotype in patients with nonsyndromic hearing loss. These previous studies were compared and summarized in Table I $(13,19,20)$. In these results, the proportion of patients with GJB4 variants was determined to be $4.09 \%$ (21/513). The present study identified that variation in GJB4 is the second most common genetic risk factor in the $\mathrm{Cx}$ gene family for the development of hearing loss in this population. In addition, the phenotype of patients with variants of Cx30.3 included prelingual, bilateral, severe-to-profound hearing loss. A flat audiometric configuration was also more frequently detected in patients with GJB4 (Cx30.3) variants compared with patients with $G J B 2$ variants.

In total, $>20$ different $\mathrm{Cx}$ proteins have been identified in mammals. They all share a common structure, however, each has its own tissue distribution-specificity, electrophysiological characteristics and regulatory properties (25). Electrophysiological studies have indicated that gap junctions have multiple gating mechanisms. At least two regulation mechanisms respond to transjunctional voltage $(\mathrm{Vj})$, including $\mathrm{Vj}$ gating (fast) and loop gating (slow) (26). In addition, membrane voltage $(\mathrm{Vm})$ can also gate gap junctions, termed $\mathrm{Vm}$-gating, and by chemical factors, including the phosphorylation, $\mathrm{pH}$ and $\mathrm{Ca}^{2+}$, which is termed chemical gating (27). Therefore, patients may exhibit different phenotypes between mutations in different functional domains of the $\mathrm{Cx}$ protein.

A three-dimensional (3D) characterization of protein structures can be used to explain the functions of proteins and their disease formation associations $(28,29)$. High-resolution characterization of proteins can be provided by either experimental methods, including X-ray crystallography, nuclear magnetic resonance or computational analysis (29). However, there is a significantly higher number of known protein sequences compared with experimentally solved protein structures. Use of a method comprising reliable models of proteins, which share $\geq 30 \%$ sequence identity between known structures and target proteins $(28,30)$, may assist in understanding the function of target proteins in the absence of crystallographic structures. The crystalline structure of the gap junction channel, which is formed by human $\mathrm{Cx} 26$, has been previously described $(31,32)$ and the N-terminal and TM13 domains have been identified as important in the permeation pathway of a gap junction channel with an intracellular channel entrance, pore funnel and extracellular cavity $(31,32)$. In addition, analysis of the crystalline structure revealed that the TM2, TM4, E1 and E2 domains of $\mathrm{Cx}$ are associated with the structural organization of the hexameric connexon, and two neighbor connexons of the gap junction channel interact with the E1 and E2 domains (31). In classifying the $\mathrm{Cx}$ protein, human $\mathrm{Cx} 26$ and $\mathrm{Cx} 30.3$ are referred to as the same subgroup, termed group I or the $\beta$ group, in phylogenetic tree analysis (33). Therefore, the Cx26 crystalline structure may assist in explaining why, in the present study, mutants in the CL domain of Cx30.3 affected the degree of hearing loss compared with the other functional domains of Cx30.3. However, in the present study, the functional effect of Cx30.3 was a prediction and the real functional effect remains to be elucidated. Therefore, in order to further investigate the effect of these variants at the protein level, the 3D structure of the $\mathrm{Cx} 30.3$ protein requires investigation.

The c. $507 \mathrm{C}>\mathrm{G}$ (p.C169W) missense mutation has been found in patients with nonsyndromic hearing loss $(13,20)$. The results of the present study revealed that the heterozygous c.507C $>$ G mutation was present in the normal hearing control group. In addition, the proband containing the homozygous c.507C $>\mathrm{G}$ mutation was inherited from parents with normal hearing, suggesting that the c. $507 \mathrm{C}>\mathrm{G}$ missense mutation had a recessive inheritance pattern (13). In the present study, a patient carrying the compound heterozygous mutation, c.376G >A/c.507 C>G (p.G126T)/p.C169W), had more serious hearing loss in the right and left ears compared with a patient carrying only a heterozygous mutation (c.376G $>$ A/wt) (Fig. 2). This result demonstrated that the combination of two genetic mutations leads to a disease phenotype, however, this phenotype is not present or is present in a mild form when only one of these gene mutations is present. Analysis using the ConSeq server (34), a web server for the identification of 
structurally and functionally important residues in protein sequences, determined that the location of position 169 in the Cx30.3 protein was at E2, which is exposed and highly conserved throughout evolution. The variants of p.C169 at E2 may result in incompatibility between the different species of connexin proteins to form heterotypic functional channels (35). Therefore, in the present study, it was hypothesized that the c. $507 \mathrm{C}>\mathrm{G}$ mutant of $G J B 4$ is a modifier and risk factor in the development of hearing loss.

In addition, no vestibular symptoms or skin disorders were found in patients with GJB4 gene variants. Notably, one patient with the c.370 C>T heterozygous genotype had inner ear and middle ear deformities on CT analysis, whereas the other patients with $\mathrm{Cx} 30.3$ variants were normal. Therefore, it was suggested that c. $370 \mathrm{C}>\mathrm{T}$ heterozygous variants of $G J B 4$ provide an important base for improving the clinical diagnosis of deaf patients with inner ear and middle ear deformities.

The present study demonstrated that GJB4 may be genetic risk factor for the development of nonsyndromic hearing loss, and the data can be applied for the effective clinical evaluation and management of care for families of children with GJB4. Further investigation will be required to understand how interference of the mutation contributes to hearing loss. In addition, it may used in future prenatal genetic analysis.

\section{Acknowledgements}

This study was supported by the National Science Council, Republic of China (nos. NSC 98-2320-B-040-016-MY3 and NSC 101-2320-B-040-014) and the Ministry of Science and Technology (MOST 103-2320-B-040-021-MY3).

\section{References}

1. Bitner-Glindzicz M: Hereditary deafness and phenotyping in humans. Br Med Bull 63: 73-94, 2002.

2. Apps SA, Rankin WA and Kurmis AP: Connexin 26 mutations in autosomal recessive deafness disorders. A review. Int J Audiol 46: 75-81, 2007.

3. Birkenhäger R, Aschendorff A, Schipper J and Laszig R: Non-syndromic hereditary hearing impairment. Laryngorhinootologie 86: 299-309, 2007.

4. Resendes BL, Williamson RE and Morton CC: At the speed of sound: gene discovery in the auditory system. Am J Hum Genet 69: 923-935, 2001.

5. Steel KP, Barkway C and Bock GR: Strial dysfunction in mouse with cochleo-saccular abnormalities. Hear Res 27: 11-26, 1987.

6. Phelan P: Innexins: members of an evolutionary conserved family of gap-junction proteins. Biochim. Biophys. Acta. Biomem 1711: 225-245, 2005.

7. Bruzzone R, White TW and Paul DL: Connections with connexins the molecular-basis of direct intercellular singnalling. Eur J Biochem 238: 1-27, 1996.

8. Spicer SS and Schulte BA: The fine structure of spiral ligament cells relates to ion return to the stria and varies with place-frequency. Hear Res 100: 80-100, 1996.

9. Kelley PM, Abe S, Askew JW, Smith SD, Usami S and Kimberling WJ: Human connexin 30 (GJB6), a candidate gene for nonsyndromic hearing loss: molecular cloning, tissue-specific expression, and assignment to chromosome 13q12. Genomics 62: 172-176, 1999.

10. Lautermann J, ten Cate WJ, Altenhoff P, Grummer R, Traub O, Jahnke $\mathrm{K}$ and Winterhager E: Expression of the gap-junction connexins 26 and 30 in the rat cochlea. Cell Tissue Res 294: 415-420, 1998.

11. Xia AP, Ikeda K, Katori Y, Oshima T, Kikuchi T and Takasaka T: Expression of connexin 31 in the developing mouse cochlea. Neuro Report 11: 2449-2453, 2000.
12. Liu XZ, Xia XJ, Adams J, Chen ZY, Welch KO, Tekin M, Ouyang XM, Kristiansen A, Pandya A, Balkany T, Arnos KS and Nance WE: Mutations in GJA1 (connexin 43) are associated with non-syndromic autosomal recessive deafness. Hum Mol Genet 10: 2945-2951, 2001.

13. Yang JJ, Huang SH, Chou KH, Liao PJ, Su CC and Li SY: Identification of mutations in members of the connexin gene family as a cause of nonsyndromic deafness in Taiwan. Audiol Neurootol 12: 198-208, 2007.

14. Steel KP and Kros CJ: A genetic approach to understanding auditory function. Nate Genet 27: 143-149, 2001

15. Yang JJ, Liao PJ, Su CC and Li SY: Expression patterns of connexin 29 (GJE1) in mouse and rat cochlea. Bioche Biophy Res Comm 338: 723-728, 2005.

16. Kikuchi T, Kimura RS, Paul DL and Adams JC: Gap junctions in the rat cochlea immunohistochemical and ultrastructural analysis. Anat Embryol 191: 101-118, 1995.

17. Forge A, Becker D, Casalotti S, Edwards J, Marziano N and Nevill G: Gap junctions in the inner ear: comparison of distribution patterns in different vertebrates and assessement of connexin composition in mammals. J Comp Neurol 467: 207-231, 2003.

18. Wang WH, Yang JJ, Lin YC, Yang JT and Li SY: Novel expression patterns of connexin 30.3 in adult rat cochlea. Hear Res 265: 77-82, 2010.

19. López-Bigas N, Melchionda S, Gasparini P, Borragán A, Arbonés ML and Estivill X: A common frameshift mutation and other variants in GJB4 (connexin 30.3) analysis of hearing impairment families. Hum Mutat 19: 458, 2002.

20. Yang JJ, Wang WH, Lin YC, Weng HH, Yang JT, Hwang CF, Wu CM and Li SY: Prospective variants screening of connexin genes in children with hearing impairment: genotype/ phenotype correlation. Human Genetics 128: 303-313, 2010.

21. Mazzoli M, Van Camp G, Newton V, Giarbini N and Declau F and Parving A: Recommendations for the description of genetic and audiological data for families with nonsyndromic hearing impairment, 2003. AvailableatHereditaryHearingLoss Homepage, http://hereditaryhearingloss.org/main.aspx?c=.HHH\&n=86638. Accessed, 2014.

22. American College of Medical Genetics: Genetics Evaluation Guidelines for the Etiologic Diagnosis of Congenital Hearing Loss. Genetic Evaluation of Congenital Hearing Loss Expert Panel. ACMG statement. Genet Med 4: 162-171, 2002.

23. Hişmi BO, Yilmaz ST, Incesulu A and Tekin M: Effects of GJB2 genotypes on the audiological phenotype: variability is present for all genotypes. Int J Pediatr Otorhinolaryngol 70: 1687-1694, 2006.

24. Liu XZ, Pandya A, Angeli S, Telischi FF, Arnos KS, Nance WE and Balkany T: Audiological features of GJB2 (connexin 26) deafness. Ear Hear 26: 361-369, 2005.

25. Evans WH and Martin PE: Gap junctions: structure and function (Review). Mol Membr Biol 19: 121-136, 2002.

26. Bukauskas FF, Bukauskiene A, Bennett MV, Verselis VK: Gating properties of gap junction channels assembled from connexin 43 and connexin 43 fused with green fluorescent protein. Biophys J 81: 137-152, 2001.

27. Bukauskas FF and Verselis VK: Gap junction channel gating. Biochim Biophys Acta 1662: 42-60, 2004.

28. Bordoli L, Kiefer F, Arnold K, Benkert P, Battey J and Schwede T: Protein structure homology modeling using SWISS-MODEL workspace. Nat Protoc 4: 1-13, 2009.

29. Sasin JM and Bujnicki JM: COLORADO3D, a web server for the visual analysis of protein structures. Nucleic Acids Research 32: W586-W589, 2004.

30. Melo F and Feytmans E: Assessing protein structures with a non-local atomic interaction energy. J Mol Biol 277: 1141-1152, 1998.

31. Maeda S, Nakagawa S, Suga M, Yamashita E, Oshima A, Fujiyoshi Y and Tsukihara T: Structure of the connexin 26 gap junction channel at $3.5^{\circ} \mathrm{A}$ resolution. Nature 458: 597-604, 2009.

32. Nakagawa S, Maeda S and Tsukihara T: Structural and functional studies of gap junction channels. Curr Opin Struct Biol 20: 423-430, 2010.

33. Beyer EC and Berthoud VM: The family of connexin gene. In: Connexin: A Guide. Harris, A and Locke, D (eds). Humana Press, Springer, USA, pp3-26, 2009

34. Berezin C, Glaser F, Rosenberg J, Paz I, Pupko T, Fariselli P, Casadio R and Ben-Tal N: ConSeq: the identification of functionally and structurally important residues in protein sequences. Bioinformatics 20: 1322-1324, 2004.

35. Krutovskikh V and Yamasaki H: Connexin gene mutations in human genetic diseases. Muta Res 462: 197-207, 2000. 